\title{
Contribuições da psicanálise ao estudo das inter- relações entre saúde mental e trabalho na categoria profissional dos operadores de tráfego
}

\author{
Valmir Antonio Zulian de Azevedo e Sérgio Roberto de Lucca \\ Universidade Estadual de Campinas
}

\begin{abstract}
Os autores fazem uma sucinta apresentação dos principais modelos explicativos das inter-relações entre saúde mental e trabalho e propõe um aprofundamento do conhecimento do polo saúde mental a partir da aplicação do conceito de psiquismo. Para dar suporte a isso, fundamentam-se em conceitos teóricos e metodológicos da psicanálise. Um estudo de caso em que o método foi aplicado é exposto. Trata-se do estudo de um grupo de operadores de tráfego de uma grande cidade. O estudo revela conflitos emocionais e seus aspectos intrapsíquicos, entre eles a angústia, os conflitos entre as instâncias do id, ego e super-ego, e os mecanismos psíquicos da dinâmica grupal. Dessa forma, a psicanálise dá suas contribuições para o entendimento dos conflitos e do que se passa no psiquismo dos operadores de tráfego durante seu trabalho, sendo capaz de, com suas teorias e métodos, estender suas aplicações ao estudo das inter-relações entre saúde mental e trabalho em outras categorias profissionais.
\end{abstract}

Palavras-chave: Saúde mental, Operadores de trafego, Psicanálise.

Contributions of psychoanalysis to study of relationships between mental health and work in the professional category of traffic operators

The author presents the main models to explain the relationships between mental health and work and proposes to deepen the knowledge about the mental health pole, with the application of the concept of psychism. To support this, bases himself on theoretical and methodological concepts of psychoanalysis. A case study with the application of the method was exposed. It is a study about a group of traffic operator of a big city. The study reveals emotional conflicts and their intra-psychic aspects, among them are the angst, the conflicts among id, ego and super-ego, and the psychic mechanism of the groups dynamics. In this way, the psychoanalysis gives their contributions to the understanding of these conflicts and reveal what happen in the mind of the traffic operator during their work, being able, with their theories and methods to extend these applications to the study of the relationships between mental health and work in other professional categories.

Keywords: Mental health, Traffic operators, Psychoanalysis.

\section{Introdução}

Segundo estimativas da OMS, os transtornos mentais menores acometem cerca de $30 \%$ dos $\checkmark$ trabalhadores ocupados, enquanto que os transtornos mentais graves, 5 a 10\%. No Brasil, o número de benefícios previdenciários por incapacidade para o trabalho, superiores a quinze dias, devido transtornos mentais e comportamentais relacionados ao trabalho, superou doze mil casos no ano de 2008 (Ministério da Previdência Social, 2008).

O trabalho representa uma importante instância no desencadeamento ou no agravamento e na evolução de transtornos psíquicos. No atual cenário econômico, no âmbito coletivo, observa-se acentuada reestruturação produtiva, precariedade das relações de trabalho, intensificação do ritmo de trabalho, exigência de polivalência e maior competitividade. No individual, o medo de perder o emprego, as metas cada vez mais desafiadoras repercutem na esfera psíquica desses trabalhadores, que dependendo do modo individual de responder a esses estímulos e de interagir, pode desencadear sofrimento e adoecimento. 
Nesse sentido, o tema saúde mental e trabalho vem sendo estudado por vários profissionais e pesquisadores. As inter-relações entre saúde mental e trabalho são abordadas atualmente por três principais modelos explicativos: a teoria do estresse, a psicopatologia e a psicodinâmica do trabalho e a teoria do desgaste bio-psico-social.

A teoria do estresse repousa sobre o conceito de síndrome geral de adaptação, um conjunto de reações que um organismo desenvolve ao ser submetido a uma situação que exige esforço de adaptação (Seley, 1956).

Quando esse esforço de adaptação se refere ao trabalho, o estresse é entendido como um desequilíbrio entre fatores específicos, que são capazes de desencadeá-los ou de causá-los e a capacidade dos trabalhadores de responderem a eles (Kalimo, 1986).

Formulações teóricas mais influentes referem que a combinação entre grandes demandas no trabalho e baixa capacidade de decisão são propiciadoras de estresse profissional e revelam um ambiente de trabalho patogênico (Karasek \& Theorell, 1990).

A fundamentação biológica dessa teoria no mecanismo neuroendócrino de alça de feedback, mais conhecido como cascata do estresse, bem como a ampliação de sua abrangência para o campo psicossocial propiciaram sua ampla difusão na medicina e na psicologia e alavancaram o desenvolvimento de práticas de investigação clínica e de tratamento, de tal forma que sua força explicativa e sua capacidade operativa fazem dela o modelo prevalecente (Frankenhaeuser \& Johansson, 1986).

Sua inclusão como categoria diagnóstica na Classificação Internacional das Doenças possibilita aos médicos a adoção desse registro como um diagnóstico generalizante de todo e qualquer distúrbio psíquico ou psicossomático, associado ao trabalho ou não, o que indubitavelmente empobrece a diversidade e a complexidade dos fenômenos e oculta aspectos específicos, reveladores das relações entre saúde mental e trabalho.

A crítica a esse modelo refere-se à questão subjetiva relacionada ao estresse, pois, enquanto modelo útil para levantar fatores de risco no ambiente de trabalho e entre categorias profissionais, não oferece perspectiva de como ocorrem essas interações das situações e processos de trabalho no intrapsíquico (subjetividade) que explicam a psico-patogênese (Pinto Silva \& Heloani, 2007; Seligman-Silva, 1995).

O segundo modelo explicativo - a psicopatologia e a psicodinâmica do trabalho - está voltado para a investigação e a análise dos conflitos que emergem do encontro do sujeito, portador de uma história singular preexistente a esse encontro, e uma situação de trabalho cujas características são em grande parte definidas independentemente da vontade do sujeito. Dois conceitos são centrais no seu arcabouço teórico: sofrimento mental e estratégias defensivas. Aquele é resultante da organização do trabalho e de suas características: a divisão do trabalho, o conteúdo das tarefas, o sistema hierárquico, as modalidades de comando, as relações de poder, as responsabilidades; e se expressam de dois modos: a insatisfação (decorrente de trabalhos de conteúdo significativo pouco valorizado) e a ansiedade, relacionada à degradação do funcionamento mental e do equilíbrio psico-afetivo, à degradação do organismo e à imperiosa necessidade de trabalhar para sobreviver, também conhecida como "disciplina da fome" (Dejours, 1987).

As estratégias defensivas referem-se a mecanismos de defesa coletivos suscitados frente ao sofrimento psíquico. $\mathrm{O}$ alvo das estratégias defensivas é minimizar a percepção de certas pressões organizacionais irredutíveis. Tais estratégias funcionam como regras, com as quais o indivíduo concorda, devendo em relação a elas realizar uma harmonização de seus outros recursos individuais para garantir a coerência de sua economia psíquica singular. Operam de forma a alterar a percepção da realidade - a organização do trabalho e o sofrimento por ela engendrado são negados - para, então, reconstruí-la coletivamente. À medida que as estratégias de defesa se tornam um programa de ação coletiva, assumem o caráter de ideologia 
defensiva, que desemboca em conflitos de poder, ou seja, no campo da luta política (Dejours, 1990).

De acordo com Dejours (1994), a evolução da psicopatologia do trabalho para a psicodinâmica do trabalho acompanha a passagem da problemática da personalidade para a da identidade. Esta é conquistada pelo trabalhador nos meandros da dinâmica intersubjetiva dentro do trabalho, através da realização de si mesmo no campo das relações sociais. Assim, o reconhecimento seria capaz de transformar o sofrimento mental em prazer, mediante a construção de um senso de trabalho considerado essencial à identidade do indivíduo.

A crítica a esse modelo é sobre a ênfase de Dejours à analise do discurso e dos aspectos subjetivos dos sujeitos, desconsiderando-se a dialética entre o subjetivo e social (Lima, 2002; Jacques, 2003). Contrapondo-se a essa visão, alguns autores demonstram que as teses centrais do autor reiteram na produção atual as relações entre os processos de saúde-doença do trabalhador, a organização e a gestão do trabalho, assim, a proposta dejouriana caracteriza-se como uma abordagem crítica e qualitativa do tema subjetividade, poder e trabalho, assumindo as feições dos estudos de caso ou da pesquisa-ação (Jacques, 2003; Heloani \& Lancman, 2004).

O terceiro modelo explicativo é erigido a partir do conceito de desgaste bio-psicosocial, sendo este o resultado de uma correlação desigual de força no processo saúde-doença (Seligmann-Silva, 1986).

O conceito de desgaste pode ser tomado como um paradigma integrador que permite compreender as interações entre os fatores objetivados pelos estudos do work stress, a subjetividade e as diferentes esferas da vida social a partir dos âmbitos microssociais do local de trabalho e da família, passando pelos intermediários - empresa e comunidade - até os macrossociais, que definem desde a divisão internacional do trabalho às políticas industrial, tecnológica e salarial de cada país, balizando as relações sociais de trabalho em cada realidade. Seligmann-Silva (1995) destaca os aspectos fundamentais a serem considerados nas abordagens teóricas e na pesquisa: o caráter permanente do processo bio-psico-social; sua multiplicidade de componentes (sociais, culturais, biológicos, psicológicos); sua elevada complexidade ao articular processos subjetivos, processos biológicos, histórias de vida, processo de trabalho e processo saúde-doença; a centralidade do conceito de sofrimento mental; a importância da perspectiva diacrônica (estudos longitudinais das trajetórias de vida e de trabalho dos indivíduos); a relevância das formas de relacionamento interpessoal nos locais de trabalho na configuração de instâncias coletivas.

Cada um desses modelos tem uma concepção mais ou menos elaborada do objeto que se deseja estudar, qual seja, o das inter-relações entre saúde mental e trabalho.

Segundo Jacques (2003), a abordagem clínica de base psicanalítica da psicodinâmica do trabalho e abordagens do bio-psico-social alinham-se à pesquisa qualitativa, enquanto que as abordagens cognitivas comportamentais (estresse no trabalho) podem ser caracterizadas pelo uso de metodologias quantitativas.

Nesse aspecto, em particular, a psicanálise pode dar sua contribuição singular para a formulação teórica e metodológica, ao trazer para este campo a reflexão sobre o aquilo que é o seu objeto primordial - o psiquismo ou a mente - e, daí, suas inter-relações com o trabalho. Ela distingue-se da psicopatologia e da psicodinâmica do trabalho - modelo este que se inspira em concepções psicanalíticas para elaborar as suas próprias - na medida em que opera com conceitos e métodos clássicos e originais, consagrados na clínica psicanalítica individual e grupal.

Psíquico é o conteúdo ou a qualidade dos processos econômicos e dinâmicos que se passam na mente ou no psiquismo. A marca do que é psíquico ou do psiquismo é a existência do conflito: a) entre diferentes sistemas psíquicos: a oposição entre o inconsciente, o préconsciente e o consciente; b) entre diferentes instâncias psíquicas: as inter-relações entre o id, 
o ego e o superego; c) entre as pulsões: sexuais e de auto-conservação, sexuais e do ego, de vida e de morte; d) entre desejos e entre estes e a interdição: o conflito edípico (Laplanche \& Pontalis, 1986).

Embora não tenha sido o objeto primordial de suas elaborações, a inter-relação entre o psiquismo e o trabalho foi assim abordada por Freud (1974), fundador e principal autor da psicanálise:

Não é possível, dentro dos limites de um levantamento sucinto, examinar adequadamente a significação do trabalho para a economia da libido. Nenhuma outra técnica da vida prende o indivíduo tão firmemente à realidade quanto a ênfase concedida ao trabalho, pois este, pelo menos, fornece-lhe um lugar seguro numa parte da realidade, na comunidade humana. A possibilidade que essa técnica oferece de deslocar uma grande quantidade de componentes libidinais, sejam eles narcísicos, agressivos ou mesmo eróticos para o trabalho profissional, e para os relacionamentos humanos a ele vinculados, empresta-lhe um valor que de maneira alguma está em segundo plano quanto ao que goza como algo indispensável à preservação e justificação da existência em sociedade. A atividade profissional constitui fonte de satisfação especial, se for livremente escolhida, isto é, se por meio da sublimação, tornar possível o uso de inclinações existentes, de impulsos persistentes ou constitucionalmente reforçados.

Com esse enfoque, Freud abre a discussão do trabalho e suas relações com as pulsões.

A pulsão é um processo dinâmico que consiste em uma pressão ou força que faz tender o organismo para um alvo. Emerge na fronteira entre o mental e o somático e, como representante psíquico dos estímulos que se originam dentro do organismo e alcançam a mente, não pode jamais tornar-se objeto da consciência, a não ser através da representação a qual está ligada - o afeto (Laplanche \& Pontalis, 1986).

Interessa-nos, para o entendimento das relações da pulsão com o trabalho, situá-la em uma perspectiva que nos dê visibilidade, qual seja, a da abordagem dos seus destinos: a sublimação, a transformação em seu contrário, o retorno ao próprio eu e o recalcamento.

A sublimação é mais comumente associada ao trabalho. Trata-se de um processo que diz respeito à libido objetal e consiste no fato de a pulsão dirigir-se no sentido de uma finalidade diferente e afastada da finalidade da satisfação sexual. A pulsão ao ser sublimada pode dirigir-se para as realizações artísticas, científicas, esportivas e, também, para o trabalho.

Muito embora o trabalho cotidiano e operacional possa ser um tipo de dessexualização da libido (Nasio, 1989) que não se eleva ao status estético da obra de arte, o seu sentido geral está voltado para um fim sublimado: o erguimento e o aperfeiçoamento da civilização (Lacan, 1988).

A transformação em seu contrário e o retorno ao próprio eu encontra sua melhor exemplificação nos estudos clínicos sobre o sadismo-masoquismo (Freud, 1974). As relações desse tipo de perversão sexual com o trabalho revelam-se desde formas mais explícitas - a escravidão - até as mais sutis práticas de harassment dos dias de hoje.

O recalcamento, por sua vez, separa o afeto de sua representação. O destino desta é o inconsciente e o afeto se manifesta como angústia, sintoma ou deslocamento para ou representação tolerável ao ego.

A angústia e suas várias modalidades - frente a um perigo real, fóbica, histérica, obsessiva, persecutória, depressiva, psicossomática - emergem nas mais diversas situações que indivíduos enfrentam no mundo do trabalho.

Alguns estudos sobre transtornos mentais entre categorias profissionais demonstram uma elevada prevalência entre professores (Porto et al., 2006; Reis et al., 2005), profissionais de 
saúde (Cabana et al., 2007; Pinho \& Araújo, 2007) e atividades econômicas específicas, tais como serviços bancários (Silva, 2007) e telemarketing (Venco, 2006).

Em um estudo realizado com um grupo de operadores fiscais e supervisores de tráfego de uma grande cidade (categoria profissional até então não estudada em relação às interrelações entre saúde mental e trabalho), foi possível, à luz dos conhecimentos e das técnicas da psicanálise, identificar mecanismos psicodinâmicos individuais e grupais operantes e, através da interpretação, dar sentido a eles.

O estudo justifica-se, em função de ter essa categoria profissional ganhado visibilidade e importância estratégica nas grandes cidades e de ser o ambiente de trabalho - os sistemas de trânsito e de transportes - em que laboram um caldeirão de tensões. Justifica-se, também, em razão do ineditismo do tipo de abordagem teórica e metodológica dessa categoria profissional.

\section{Método}

O método de investigação aplicado a um grupo de operadores fiscais e supervisores de tráfego fundamenta-se nos conceitos técnicos da prática psicanalítica aplicável a grupos de pessoas. São elementos técnicos indispensáveis ao método: a criação de um ambiente adequado para as sessões, o estabelecimento de um contrato verbal entre pesquisador e participantes do grupo, a associação livre de ideias, a valorização das expressões do inconsciente (afetos, atos falhos, chistes, atuações) dos participantes do grupo, a consideração dos fenômenos de transferência e contratransferência e a interpretação.

A dinâmica de uma sessão consiste em o pesquisador convidar os participantes a falar livremente sobre o que pensam e sentem quando estão trabalhando. No curso das manifestações dos participantes, aspectos do inconsciente que emergem são captados pelo pesquisador - um profissional com formação e prática em psicoterapia psicanalítica. Em alguns momentos, uma intervenção interpretativa pode ser feita, estimulando os participantes a falarem mais sobre um determinado assunto ou direcionando o foco da atenção para um determinado tema. Eventualmente durante, mas principalmente logo após o seu término, o pesquisador faz anotações por escrito relatando o que se passou na sessão (falas, emoções, atos falhos, atuações). A cada duas ou três sessões o pesquisador submete o material das sessões à supervisão de profissional experiente e que lhe dá retroalimentações sobre a condução do trabalho.

Com a finalidade de realizar-se uma pesquisa de campo para uma tese de doutoramento, este pesquisador entrou em contato com uma empresa que controla o tráfego de uma grande cidade brasileira e, após expor seu projeto, foi autorizado a realizar a pesquisa com os trabalhadores. Um grupo de oito operadores fiscais e supervisores de tráfego, sendo quatro homens e quatro mulheres, foi selecionado aleatoriamente de um contingente de pouco mais de vinte indivíduos que trabalhavam há mais de cinco anos nessa atividade na empresa.

Foi estabelecido um contrato com o grupo para definir os objetivos e as regras do trabalho. A proposição de realizar-se um encontro semanal durante dez semanas consecutivas com todos os membros do grupo em uma sala apropriada no local de trabalho foi aceita. Em cada encontro os participantes eram convidados a falar livremente e a expressar suas ideias e seus sentimentos em relação ao próprio trabalho. Em alguns poucos momentos, o pesquisador interveio para fazer aflorarem falas e emoções. Algumas anotações, feitas durante cada encontro, e a elaboração (secundária) de um relatório ao final de cada uma das sessões foram as formas de registro do material do encontro por parte do pesquisador. 
A supervisão das sessões e dos seus relatórios foi feita por um supervisor especializado em psicoterapia de grupo.

O material escrito foi utilizado como referência para a articulação das vivências dos trabalhadores com a teoria psicanalítica, utilizada como referencial teórico, devido a sua capacidade de entender o que se passa no psiquismo humano, nas diferentes situações de vida de um indivíduo.

\section{Descrição do caso}

Em um contexto de mudança do sistema de tráfego de uma grande cidade, em que uma série de medidas reorganizadoras e disciplinadoras foi implementada, com o objetivo de reduzir as ocorrências graves e fatais, foi introduzido em cena o personagem dos operadores fiscais e supervisores de tráfego, cujas ações consistiam em orientar, fiscalizar e autuar os motoristas e pedestres.

Esse projeto fora liderado por um presidente da empresa bastante considerado, tendo em vista seu conhecimento e sua experiência no assunto. Um compromisso ético e profissional fora selado entre ele e os operadores e supervisores de tráfego para atingir o objetivo proposto. Estes, por sua vez, estavam convictos e orgulhosos da missão que tinham pela frente.

As reações de hostilidade de uma parcela da população ao trabalho dos operadores fiscais e supervisores de tráfego não tardaram a aparecer. Ameaças, constrangimento, agressões verbais e físicas sofridas por todos eles, mas principalmente pelas mulheres, foram registradas.

À parte os desafios da rotina de trabalho que cada um, pessoalmente, tinha que enfrentar - atender vítimas de acidentes de trânsito, mediar conflitos entre motoristas, decidir e orientar o tráfego em situações de emergência - durante vários anos seguidos, a tensão e o medo gerados pelos conflitos com uma minoria de cidadãos insatisfeitos fizeram parte do cotidiano de seu trabalho. No entanto, eles se sentiam amparados pela direção da empresa.

Uma mudança na presidência da empresa e consequentemente na sua condução havia recentemente ocorrido: novos conceitos, novas normas, novas contratações criavam um clima de expectativa e incertezas. Este trabalho esteve em curso nesse período.

\section{Discussão}

$\mathrm{Na}$ presente discussão pretende-se, a partir dos conteúdos emocionais e dos mecanismos de defesa operantes, revelados através da atividade interpretativa dos discursos dos participantes do grupo, estabelecer associações com aspectos teóricos e metodológicos da psicanálise, qual sejam: aqueles oriundos das elaborações de Freud e os da teoria psicanalítica aplicada a grupos, de Bion (1975). As interpretações a seguir apresentadas referem-se ora a aspectos da psicodinâmica do grupo, ora a aspectos psíquicos individuais que dão sentido às vivências emocionais dos seus participantes, tendo sempre como referência o seu mundo de trabalho.

A atividade interpretativa no grupo constitui-se como seu principal instrumento técnico, sendo que não existem fórmulas acabadas e "certas" de como e o que dizer, pois as situações práticas são muito variáveis (Zimerman, 2001). 
Essas interpretações são o produto do material - discursos e emoções subjacentes extraído em um enquadramento específico. Com aqueles participantes, com este pesquisador, em um determinado contexto da história da empresa, foi possível tecer uma rede de significados para as palavras e os afetos evocados. É uma produção única e singular. Obtém-se sua validação na medida em que a reflexão e seu sentido são acolhidos pelo grupo. É uma verdade, entre as tantas possíveis para esse grupo. Outras seriam possíveis mesmo com esse grupo em outro contexto, ou com um grupo diferente desse, ou com esse grupo e um pesquisador outro. Bastaria a presença de um outro participante para gerar outras produções psíquicas e outros significados possíveis.

Tomando-se a psicanálise como um saber cujo objeto é a relação do desejo com a cultura - nela incluída o mundo do trabalho - e cuja especificidade reside na atividade de simbolizar as simbolizações originárias (Jupiassu, 1988), considera-se que o desejo fugindo à apreensão das técnicas científicas clássicas é captado através da intersubjetividade de uma relação humana específica, que se deixa, propositalmente, "contaminar-se" com a emoção, para lhe revelar o sentido e produzir a partir dele um conhecimento que vai além da ciência, para situar-se na interface entre os campos da ética, da cultura e da ciência.

Esse sentido é impresso pela atividade interpretativa que revela os conteúdos latentes (inconscientes) existentes nas manifestações (palavras, sintomas, atos falhos, obras) de um sujeito ou dos sujeitos de um grupo escutado pelo psicanalista ou investigados pelo pesquisador sob a ótica do saber psicanalítico.

Tomando-se uma embocadura freudiana do material oriundo dos discursos e das emoções neles presentes, pode-se interpretar que esse grupo de operadores de tráfego compartilha ideias e vivencia afetos relativos à sua atividade profissional que lhe confere uma identidade: o conflito psíquico, entre um lado bom, acolhedor e identificado com a dificuldade do outro, que dá prazer ao ego; e um lado mau, associado à agressividade e aos sentimentos hostis e à dor, percebido como desprazer pelo ego. Isso está presente desde o início da primeira sessão na fala de um dos operadores de tráfego: "Tem dois tipos de emoções: a boa e a ruim. Poder ajudar uma senhora, um cego, é gratificante, é o lado bom. As agressões, os desentendimentos com os colegas, os acidentes, é o lado ruim". O esforço para resolver o conflito psíquico acompanha os operadores, como manifesta outro operador: "Muitas vezes eu sonho com o meu trabalho".

O sentimento de impotência aparece em algumas situações, como no atendimento de um acidentado ou na lide com as pressões da população: "Nós captamos toda a negatividade da população e não temos capacidade para nos proteger". Ou: "Acho que precisaríamos ter mais cursos de pilotagem de RH, de postura com a população. Precisamos ter psicólogos para suporte. Nesta administração não teve nenhum curso de pilotagem de RH", "A culpa não é do fiscal, é do pessoal lá de cima".

Como são difíceis, complexos, exigentes de senso de responsabilidade e de capacidade decisória, alguns eventos geram a sensação de incapacidade para resolvê-los. No plano psicodinâmico, há um julgamento interno, uma crítica do superego ao ego, que, por sua vez, tem que lidar com algo que não domina, daí a angústia. Parte dessa angústia é elaborada e assumida para si, gerando culpa, sentimentos autodepreciadores ou consciência da impotência e parte é projetado para fora de si e colocada no outro (a direção da empresa), aliviando o psiquismo dessa tensão.

É marcante a ideia onipotente de que eles são portadores de uma verdade que deve ser reconhecida por todos aqueles a quem ela é dirigida. Essa conviç̧ão origina-se de um processo de identificação com as ideias do presidente da empresa, reconhecido por ser um estrategista de elevado conhecimento técnico, jurídico e administrativo; mentor intelectual do projeto de reformulação do sistema de tráfego de uma grande cidade, que introduziu o personagem dos operadores/fiscais de tráfego no cenário. Conforme um dos operadores: "Orientar, advertir e autuar são as atribuições dos operadores de tráfego". 
Trata-se do exercício de uma função superegóica. Esta é validada na medida em que indivíduos e vários segmentos sociais da população manifestam seu desacordo com as medidas adotadas, através de protestos, de ameaças, de ataques verbais e de agressões físicas, objetivando manter o estado "pouco regulamentado" do tráfego na cidade. Há uma função superegóica do grupo que está voltada para o cumprimento de regras, para a educação no trânsito, para a advertência tolerante das pequenas transgressões e para a punição das de maior gravidade.

Os participantes do grupo manifestam o sentimento de perda, representado pelo desligamento do presidente da empresa e, como filhos adotados por outro pai, não se sentem suficientemente investidos e valorizados. Tratam de cuidar de uma ferida narcísica aberta com a saída do pai do projeto. Há uma temática familiar, edípica: de um lado um pai-presidente normatizador, educador, com ideais elevados; do outro, uma mãe-empresa nutridora de bons salários, de um bom clima de trabalho, de serviços de apoio e, entre eles, os filhos-operadores de tráfego identificados com os aspectos superegóicos desse pai e com os nutridores dessa mãe. A morte simbólica do pai e sua substituição por outro que não os ama suficientemente faz neles emergir a angústia do desamparo, como se perguntassem: o que será de nós agora?

O conflito entre os anseios dos operadores de tráfego e os da população é capaz de produzir angústias do tipo fóbico ante ao perigo real das ameaças e das agressões verbais e físicas. As ameaças geram, além da angústia fóbica ante o perigo real, um tipo de angústia não relacionada a um evento evidenciável, mas relativa à fantasia de ser violentado(a). Essa fantasia decorre da projeção da força coercitiva da ação superegóica, da qual os operadores de tráfego estão imbuídos, sobre aqueles que transgridem a norma. O que é ruim, errado, agressivo é projetado no outro e, internamente, o ego fica aguardando, temeroso, a represália que pode vir de fora, mas que na realidade psíquica é oriunda da severidade do superego.

A angústia de tipo obsessivo aparece na medida em que a ação reguladora pertinente à atividade do operador de tráfego extrapola a esfera de atuação profissional. Isso fica evidente no relato de um dos operadores de tráfego: "Uma hora após sair do trabalho continuo agindo com se estivesse fiscalizando. Não consigo ver coisas erradas no trânsito e ficar quieto. Fico exigindo que coloquem o cinto de segurança".

Também a dúvida os acompanha. Há um conflito entre o que é certo e o que é errado: se os objetos e as pessoas estão no local onde deveriam estar, se o tempo que ultrapassa a anotação de cartão de estacionamento deve ser tolerado ou não; como uma situação que não está escrita no manual deve ser considerada é algo que tem que ser decidido pelo próprio operador. O excerto a seguir é ilustrativo:

Antes de você autuar o cidadão, você tem que se colocar no lugar dele. Alguma coisa fez com que ele cometesse a autuação. Por exemplo, na frente do hospital você tem que ver que a pessoa pode ter parado para socorrer outra pessoa. Eu já deixei de autuar um carro que tinha dentro o folheto de transplante de uma criança.

Um outro operador, por sua vez, disse:

$\mathrm{Na}$ porta de hospital e na frente do cemitério, são os locais mais difíceis de autuar. Eu já autuei um carro de um pai acompanhado da mãe que levou o filho no hospital porque ele quebrou a perna e eu argumentei que outras pessoas precisariam estacionar ali...

Outra faceta associada ao ideal do ego, identificável no discurso dos operadores de tráfego, é aquela em que se pode identificar a transformação dos impulsos agressivos e dos impulsos sexuais em impulsos amorosos, construtivos, éticos, que desejam algo bom para a população: diminuir os acidentes de trânsito e as mortes deles decorrentes. É um desejo de uma 
comunidade sem sofrimento, com uma melhor qualidade de vida. Um dos operadores expressa aspectos idealizados, sublimados do seu trabalho ao dizer:

O que mais me importa é estar servindo ao próximo. A população é quem paga o meu salário, é a ela que dedico o meu trabalho. As pessoas idosas, hoje, podem atravessar uma avenida movimentada, antes não podiam. Me orgulho disso.

Há nessa manifestação um desejo de uma sociedade mais civilizada e uma consciência sobre a responsabilidade social do trabalho do operador de tráfego. Trata-se de uma sublimação.

Um outro componente que mantêm os participantes do grupo trabalhando é sem dúvida o narcísico. Ele está associado, por um lado, à satisfação de pulsões de autoconservação obtida através da remuneração e dos demais benefícios e, por outro, ao desejo de ser reconhecido e de ser amado pela empresa e por seu novo presidente, e de ser aceito pela população. Eles já vivenciaram a boa experiência de serem amados e valorizados e esse algo bom ficou registrado em suas mentes. A pulsão de vida é que os mantêm, enquanto grupo, vivos, unidos e esperançosos. Aspectos narcísicos, que procuram valorizar o que há de bom no grupo, aparecem quando os operadores de tráfego se comparam aos policiais militares: "No nosso trabalho de fiscais, não há corrupção. Trabalhamos seis horas, temos planos de saúde, temos vale-refeição, temos um bom salário".

Há vários mecanismos de defesa operantes entre os indivíduos que compõem o grupo, desde os mais primitivos, até aqueles próprios de um ego mais evoluído. A introjeção de uma ideia oriunda de um líder; a projeção de impulsos sexuais e agressivos no outro, representado por indivíduos e setores da população; a idealização como uma forma de evitar a impotência e a frustração, representada pela ideia de uma cidade com mais segurança no trânsito, de um maior reconhecimento por parte da empresa e da população; o deslocamento, a anulação e o isolamento, próprios da forma de lidar com a angústia fóbica e com a obsessiva; a racionalização do uso do argumento lógico-científico sob o qual está alicerçada a ideia da prevenção de acidentes de trânsito; o recalque e a sublimação que operam a serviço de uma ética de relacionamento civilizado.

Em uma leitura através da concepção de Bion sobre a experiência com grupos, pode-se interpretar o que segue: o grupo movimenta-se da posição denominada grupo de trabalho, em que está em contato com a realidade externa, consciente do seu papel profissional e de agente social de uma mudança na política de tráfego de uma grande cidade, para uma posição subjacente, em que os pressupostos básicos, inconscientes, o de dependência, o de luta-fuga, e o de acasalamento estão presentes, existindo entre elas configurações variadas e alternâncias em cada sessão, muito embora, no conjunto, uma delas seja predominante.

O suposto básico de dependência está associado a uma psicodinâmica em que os membros do grupo elegem um líder capaz de protegê-los e nutri-los. Esse grupo foi amado, protegido e nutrido, tendo como líder incontestável o presidente da empresa até a sua saída. Havia, no período em que a pesquisa foi desenvolvida, uma incerteza pairando no ar, quanto a essa liderança. Inconscientemente o grupo está a procura de um líder, pois é dependente de alguém que o dirija. Internamente, ninguém tem condições de assumir a liderança. É um grupo imaturo, como uma criança que depende dos pais para lhe conduzir. Mantém-se, tendo como referência, as ideias, o projeto do ex-presidente.

A suposição básica de luta-fuga é característica de um funcionamento grupal em que angústias, pulsões hostis e agressivas são dirigidas para um inimigo comum. Esse é o mecanismo predominante no funcionamento desse grupo. Lutam contra a resistência de indivíduos e setores da população ao seu projeto, convictos de que ele é a verdade, rejeitando e punindo as transgressões e fogem das ameaças e agressões. Trata-se de projeções para fora de impulsos agressivos e que despertam, a posteriori. Angústia paranoide. Trata-se também de uma 
estratégia de dominação, em que novas regras estão sendo implantadas, tendo como componente psíquico o sadismo, de quem submete o outro a uma determina lei. São aspectos da psicodinâmica do líder desse grupo, ser exemplar na conduta, disciplinador, severo, vigilante, punitivo. $\mathrm{O}$ grupo conviveu com esse tipo de liderança superegóica e assimilou-a no seu modo de ser, no seu funcionamento psicodinâmico.

O suposto básico do acasalamento diz respeito ao fato de que o grupo espera que dele surja um par que gere um filho que poderá salvar os seus membros das dificuldades que vivem. Há uma espera messiânica de que uma pessoa, um fato, uma decisão, uma lei possa aliviar o sofrimento. O grupo em questão passa por esse momento, esperando idéias, decisões da empresa e de seu presidente, instâncias de quem elas podem vir para aliviar a angústia do desamparo que estão vivenciando.

\section{Considerações finais}

Ao contrário do que se possa imaginar, o exercício profissional não é completamente consciente e racional. É repleto de emoções e sentimentos conflituosos. Em determinadas categorias profissionais, como a dos operadores fiscais e supervisores de tráfego, poderosos mecanismo intrapsíquicos devem entrar em ação para que esse profissional, em meio às tensões próprias do trânsito e do tráfego das grandes cidades, seja capaz de oferecer um serviço equilibrado e efetivo.

A teoria e a metodologia psicanalíticas oferecem inúmeros recursos para a compreensão e a interpretação dos aspectos psicodinâmicos observados nas relações entre psiquismo e trabalho, tanto na abordagem individual, quanto na coletiva.

Além disso, os conceitos teóricos e técnicos oriundos da psicanálise, principalmente aqueles que dizem respeito à psicodinâmica, quando aplicados ao campo da saúde mental do trabalhador dão a este um suporte que contribui para o fortalecimento do seu arcabouço teórico interdisciplinar.

A aplicação da teoria e de técnicas psicanalíticas para a compreensão das inter-relações entre saúde mental e trabalho na categoria profissional dos operadores fiscais e de supervisores de tráfego traz à luz os aspectos inconscientes da dinâmica do psiquismo humano (a angústia, os conflitos entre as instâncias id, ego e superego, os mecanismo psíquicos inconscientes que permeiam os grupos), quando se põe foco na atividade profissional.

Sua aplicabilidade ao campo da saúde mental do trabalhador dependerá do interesse e da participação de profissionais com formação psicanalítica na abertura de linhas de pesquisa em institutos e universidades. Como nos últimos anos a psicanálise tem ampliado o seu campo de ação para a educação, a justiça, as artes, o terreno também está propício para desenvolvimentos similares na área do trabalho. 


\section{Referências}

Bion, W. R. (1975). Experiências com grupos. Rio de Janeiro: Imago.

Cabana, M. C. F. L., Ludemir, A. B., Silva, E. R., Ferreira, M. L. L. \& Pinto, M. E. R. (2007). Transtornos mentais comuns em médicos e seu cotidiano de trabalho. Jornal Brasileiro de Psiquiatria, 56 (1), 33-40.

Dejours, C. (1987). A loucura do trabalho: estudo de psicopatologia do trabalho. São Paulo: Oboré.

Dejours, C. \& Abdoucheli, E. (1990). Itinéraire théorique en psychopathologie du travail. Revue Prevenir, 20, 127. 149 .

Dejours, C. \& Jayet, C. (1994). Psicodinâmica do trabalho. São Paulo: Atlas.

Dejours, C. (2004). A metodologia em psicologia do trabalho. In S. Lancman \& L. Sznelwar (Orgs.), Cristhofer Dejours: da psicologia à psicopatologia do trabalho (pp. 105-126). Rio de Janeiro: Fiocruz.

Frankenhaeuser, M. \& Johansson, G. (1986). Stress at work: psychobiological and psychosocial aspects. International Review of Applied Psychology, 35, 287-99.

Freud, S. (1974). O mal-estar na civilização. In Obras psicológicas completas. Rio de Janeiro: Imago.

Heloani, J. R. \& Lancman, S. (2004). Psicodinâmica do trabalho: o método clínico de intervenção e investigação. Revista Produção, 14 (3), 77-86

Jacques, M. G. C. (2003). Abordagens teórico-metodológicas em saúde/doença mental \& trabalho. Psicologia $\mathbb{E}$ Sociedade, 15 (1), 97-116.

Japiassu, H. (1988). Psicanálise: ciência ou contraciência? Rio de Janeiro: Imago.

Kalimo, R. (1986). Assesment of occupational stress. In M. Kaovonen \& M. I. Mikheev (Eds.), Epidemiology of occupational health (pp. 231-250). Copenhagen: WHO Regional Publications.

Karasek, R. A. \& Theorell, T. (1990). The environment, the worker, and ilness: psychological and physiological linkages. In R. A. Karasek \& T. Theorell (Orgs.), Healthy work (pp. 83-116). New York: Basic Books.

Lacan, J. (1988). O seminário: a ética da psicanálise (livro 7). Rio de Janeiro: Zahar.

Laplanche, J. \& Pontalis, J. B. (1986). Vocabulário da psicanálise. São Paulo: Martins Fontes.

Lima, M. E. A. (2002). Esboço de uma crítica à especulação no campo da saúde mental e trabalho. In M. G. Jacques \& W. Codo (Orgs.), Saúde mental \& trabalho: leituras (pp. 50-81). Petrópolis: Vozes.

Ministério da Previdência Social (2008). Acompanhamento dos benefícios auxílios-doença acidentários concedidos segundo o CID-10 (janeiro a dezembro de 2008).

Nasio, J. D. (1989). Lições sobre os sete conceitos cruciais da psicanálise. Rio de Janeiro: Zahar.

Pinho, P. S. \& Araújo T. M. (2007). Trabalho de enfermagem em uma unidade de emergência hospitalar e transtornos mentais. Revista de Enfermagem da UERJ, 15 (3), 329-336.

Porto, L. A., Carvalho, F. M., Oliveira, A. M., Silvany, A. M., Araújo, T. M., Reis, E. J. F. B. \& Delcor, N. S. (2006). Associação entre distúrbios psíquicos e aspectos psicossociais do trabalho de professores. Revista de Saúde Pública, 40 (5), 818-826.

Pinto Silva, E. \& Heloani, R. (2007). Aspectos teóricos e metodológicos da pesquisa em saúde mental e trabalho: reflexões a partir de uma análise comparativa do estresse em jornalistas e guardas municipais. Cadernos de Psicologia Social do Trabalho, 10 (1), 105-120.

Reis, E. J. F. B., Porto, L. A., Carvalho, F. M., Oliveira, A. M., Silvany, A. M. \& Araújo, T. M. (2005). Trabalho e distúrbios psíquicos em professores da rede municipal de Vitória da Conquista, Bahia, Brasil. Cadernos de Saúde Pública, 21 (5), 1480-1491.

Seley, H. (1956). The stress of life. New York: McGraw-Hill.

Seligmann-Silva, E. (1995). Psicopatologia e psicodinâmica no trabalho In R. Mendes (Org.), Patologia do trabalho (pp. 287-310). Rio de Janeiro: Atheneu.

Seligmann-Silva, E. (1986). Crise econômica, trabalho e saúde mental. In V. A. Camon-Angerami (Org.), Crise, trabalho e saúde mental no Brasil (pp. 54-132). São Paulo: Traço. 
Silva, L. S., Pinheiro, T. M. \& Sakurai, E. (2007). Reestruturação produtiva, impactos na saúde e sofrimento mental: o caso de um banco estatal em Minas Gerais, Brasil. Cadernos de Saúde Pública, 23 (12), 2949-2958.

Venco, S. (2006). Tempos moderníssimos nas engrenagens do telemarketing. Tese de Doutorado, Faculdade de Educação, Universidade Estadual de Campinas, Campinas.

Zimerman, D. E. (2001). Vocabulário Contemporâneo de Psicanálise. Porto Alegre: Artmed.

\section{Endereço para correspondência}

azevedo.valmir@uol.com.br, slucca@fcm.unicamp.br

Recebido em: 31/08/2009

Revisado em: 19/01/2010

Aprovado em: 28/01/2010 